\title{
Session 2pPP
}

\author{
Psychological and Physiological Acoustics: Temporal and Spatial Factors (Poster Session) \\ Julie Bierer, Chair \\ Univ. of Washington, Dept. of Speech and Hearing Science, 1417 N.E. 42nd St., Seattle, WA 98015-6246
}

\section{Contributed Papers}

\begin{abstract}
All posters will be on display from 1:00 p.m. to 5:00 p.m. To allow contributors an opportunity to see other posters, contributors of odd-numbered papers will be at their posters from 1:00 p.m. to 3:00 p.m. and contributors of even-numbered papers will be at their posters from 3:00 p.m. to 5:00 p.m.
\end{abstract}

2pPP1. Frequency dependence of the interaural time difference thresholds in human listeners. Larisa Dunai (Departemento de Ingeniería Gráfica, Universidad Politécnica de Valencia, Camino de Vera, 46022 Valencia, Spain) and William M. Hartmann (Dept. of Phys. and Astronomy, Michigan State Univ., East Lansing, MI 48824)

Interaural time difference (ITD) thresholds for sine tones were measured as a function of frequency with unprecedented resolution along the frequency axis. The tone level was $70 \mathrm{~dB}$ SPL, and the method was a twointerval forced-choice, three-down one-up staircase. Overall, the lowest thresholds occurred near $1000 \mathrm{~Hz}$. At lower frequencies, thresholds varied more rapidly than the expected $1 / f$ law, suggesting a growing deficit in elemental ITD processors as characteristic frequency decreases. At higher frequencies, thresholds increased dramatically with increasing frequency. Measurements at $50-\mathrm{Hz}$ increments were able to obtain a threshold for only one listener at $1500 \mathrm{~Hz}$, but no threshold at $1550 \mathrm{~Hz}$. In summary, performance varied from best to impossible over a range of about half an octave. In that sense, ITD thresholds appear to show the most dramatic frequency dependence of any auditory quantity. [Work supported by the Vice-rectorate for Faculty and Academic Planning, Universidad Politécnica de Valencia and by the US NIDCD Grant No. DC-00181.]

2pPP2. A re-examination of human underwater sound localization abilities in the azimuth. Michael K. Qin (Naval Submarine Medical Res. Lab., Naval Submarine Base New London, Box 900, Groton, CT 06349), Neil Aaronson (The Richard Stockton College of NJ, Pomona, NJ 08240), Matthew Babina, and Edward Cudahy (Naval Submarine Base New London, Groton, CT 06349)

Divers are frequently exposed to underwater sounds. The subjective impression of the diving community is that sound localization underwater is extremely difficult. However, Feinstein [1973a, 1973b] found underwater minimum audible angles (MAAs) to be approximately $10 \mathrm{deg}$. To the extent that underwater MAAs reflect the general performance of the binaural system, this would suggest that humans should be reasonably effective at underwater sound localization. A re-examination of the underwater MAAs, with greater subject and environment control, was performed. The present work indicates underwater MAAs at approximately 20-30 deg, significantly poorer than previous findings. [Work supported by the ONR.]

2pPP3. Human underwater and bone conduction hearing in the sonic and ultrasonic range. Michael K. Qin, Derek Schwaller, Matthew Babina, and Edward Cudahy (Naval Submarine Medical Res. Lab., Naval Submarine Base New London, Box 900, Groton, CT 06349)

Several investigators have reported that high-intensity bone-conducted sounds in the ultrasonic range $(>20 \mathrm{kHz})$ can produce auditory sensations in individuals with normal hearing. Underwater hearing threshold studies performed at the Naval Submarine Medical Research Laboratory have found audibility curves similar to those previously reported in bone conduction studies. Human underwater and bone conduction behavioral thresholds in the frequency range between $20 \mathrm{~Hz}$ and $200 \mathrm{kHz}$ are presented. Accelerometry measurements made with a mechanical human-head simulator are also presented. The present findings support the argument that the primary mechanism for human underwater hearing is bone conduction. Possible mechanisms for the underwater ultrahigh frequency hearing will be discussed.

2pPP4. Effects of spatial visual information and head motion cues on auditory spatial judgments. Mark A. Ericson and Rachel Weatherless (Army Res. Lab., 520 Mulberry Point Rd., Aberdeen Proving Ground, MD 21005, mark.a.ericson@us.army.mil)

Virtual audio systems are commonly used today to create auditory environments for various listening tasks. The dimensions and absorption characteristics of the surrounding real visual space often do not match the virtual auditory listening space. This mismatch in spatial information has been shown to have a small or negligible effect in the perceived direction of sound sources. However, spatial cues can have a large effect on perceived auditory distance. The most veridical auditory spatial renderings are ones that match the visual space around the observer. Several experiments were conducted to investigate the effects of visual spatial information and head motion cues on perceived auditory distance. In the first experimental condition, naive observers were deprived of all visual cues while making judgments on the egocentric distance of sound sources played over loudspeakers. In the second condition, subjects were presented with mismatched visual and auditory spatial cues via a manikin. The acoustic manikin was either non-moving or would rotate in correlation with the listener's head motion. In the last (control) condition, sound sources were presented from loudspeakers with matching visual and auditory cues. The effects of the visual spatial cues and head motion cues on auditory distance judgments will be described.

2pPP5. Lateralized processing of audiovisual speech: Combining dichotic listening with visual hemifield effects. Marianne Boettiger (Dept. of Linguist., Univ. of Tuebingen, D-72076 Tuebingen, Germany, marianneboettiger@gmx.de) and Ingo Hertrich (Univ. Tuebingen, D-72076 Tuebingen, Germany)

The perception of acoustically presented speech syllables can be influenced by simultaneous visual presentation of a speaker's face uttering different syllables. Furthermore, previous studies have shown that the visual influence on the phonetic percept depends on the video signal being presented to the left or right hemifield, indicating lateralized processing of visual phonological information. The present study, combining a dichotic listening paradigm $(/ \mathrm{pa} /$ and $/ \mathrm{ta} /$ syllables $)$ with visual hemifield presentation, investigated the interactions between auditory right-ear advantage, visual hemifield effects, and participants' gender. Most of the items were perceived as $/ \mathrm{ta} /, / \mathrm{pa} /$, or $/ \mathrm{pta} /$. Apart from a strong and highly significant right-ear advantage, single consonant responses showed a right-hemifield advantage, irrespective of place of articulation and gender. By contrast, /pta/ responses were more frequent in females than males and showed an interaction of video side with place of articulation. The largest number of double articulations was perceived if right-ear $/ \mathrm{ta} / \mathrm{was}$ combined with labial lefthemifield presentation and left-ear $/ \mathrm{pa} /$. These results can be taken as an in- 